\title{
A Protest.
}

SIR, - Those librarians who, in the innocence of their hearts, imagined they were doing a public service by addressing a confidential circular to a paper called London, will now be delighted to learn that in reality they were serving Mr. Alfred Cotgreave, F.R.H.S., of West Ham, a distinguished inventor and compiler of a cyclopæedian catalogue as big as the island of Guemsey. The replies to the circular mentioned have been tabulated and printed on a large folio sheet and, after being distributed at Belfast by Mr. Cotgreave, will no doubt in the future form a permanent advertisement of the famous red and blue indicator with which most librarians have been made familiar. As a piece of commercial sharpness, the dodge of getting a number of testimonials under cover of information for a so-called "progressive journal" was clever, but whether it will be considered dignified or proper by those who were fooled into giving opinions, is quite another thing. It is most disgraceful that half the public librarians in Britain should be tricked into gratuitousiy advertising a piece of library furniture on the pretence that they were 2ssisting in a plebiscite on a question of library management. After this, the action of London and those behind it who were responsible for the series of attacks on the Clerkenwell Public Library can be judged with considerable accuracy, and the value of the criticism assessed at its true value.

COUNTRY LIBRARIAN.

\section{Catalogue Criticisar.}

SIR, - I cordially agree with everything Messrs. Folkard and Pacy have written on the question of catalogue criticism, and beg to express my earnest hope that you will not discontinue it, though I should like to see it conducted on somewhat different lines. The truth is that the great majority of library catalogues, especially those compiled on the so-called "dictionary" plan for lending libraries, are no better in design than they were twenty years ago, though the idea seems to be widely prevalent that the high-water mark of perfection has been reached. It is, therefore, not only criticism that is wanted, but suggestion and instruction on points in cataloguing which are almost invariably neglected. Your critics bave favoured us from time to time with remarks on what Mr. Pacy aptly terms "microscopic" deficiencies-misprints, abuse of capitals, turned letters, misuse of the dash-but they have very rarely spoken out on certain vital principles of cataloguing which closely concern the public. I refer to the matler contained in catalogues, the proper representation of important authors and subjects; the characterization or explanation of misleading and obscure titles; and due regard to accuracy of entry. I have little hesitation in stating that not a single lending library catalogue issued during the past twenty years will pass a close scrutiny on any of these points. I have before me various catalogues issued during $1893-4$, every one being compiled on the lines of a wholesale grocer's price-list, and no more likely to aid the public with regard to the subject-matter of books than if they were devoted to an inventory of drugs. It is true that most of the books in the libraries are named in these calalogues, but not one tries to instruct readers in what the books are about. For example, what can an ordinary reader make of such entries under authors' names as :-

Lamont. Sensons with the sea-horses;

or

Warburton. Crescent and the cross ? 